LAWRENCE LIVERMORE NATIONAL LABORATORY

\title{
Performance of a New Lightweight Reciprocating Pump
}

John C. Whitehead

\section{July 10, 2005}

$41^{\text {st }}$ AIAA/ASME/SAE/ASEE

Joint Propulsion Conference and Exhibit

Tucson, AZ

Paper Number AIAA-2005-3921

AIAA = American Institute of Aeronautics and Astronautics

ASME = American Society of Mechanical Engineers

SAE = Society of Automotive Engineers

ASEE = American Society of Engineering Education 
This document was prepared as an account of work sponsored by an agency of the United States Government. Neither the United States Government nor the University of California nor any of their employees, makes any warranty, express or implied, or assumes any legal liability or responsibility for the accuracy, completeness, or usefulness of any information, apparatus, product, or process disclosed, or represents that its use would not infringe privately owned rights. Reference herein to any specific commercial product, process, or service by trade name, trademark, manufacturer, or otherwise, does not necessarily constitute or imply its endorsement, recommendation, or favoring by the United States Government or the University of California. The views and opinions of authors expressed herein do not necessarily state or reflect those of the United States Government or the University of California, and shall not be used for advertising or product endorsement purposes. 


\title{
Performance of a New Lightweight Reciprocating Pump
}

\author{
John C. Whitehead ${ }^{*}$ \\ Lawrence Livermore National Laboratory, Livermore, CA 94551
}

\begin{abstract}
A new four-chamber piston pump design has been fabricated and tested. The small-scale propellant pump is intended to be powered by gas at elevated temperatures, e.g. in a gasgenerator cycle rocket propulsion system. Two key features are combined for the first time: leak-tight liquid-cooled seals, and a high throughput per unit hardware mass. Measured performance curves quantify flows, pressures, leakage, volumetric efficiency, and tank pressure requirements. A pair of 300-gram pumps operating with significant margin could deliver fuel and oxidizer at $5 \mathrm{MPa}$ to a compact lightweight 1000-N engine, while tank pressure remains at 0.35 MPa. Pump weight is well below one percent of thrust, as is typical for launch vehicle engines. Applications include small upper stages, aggressive maneuvers in space, and miniature launch vehicles for Mars ascent.
\end{abstract}

\section{Introduction}

Rocket propellant pumps reduce the size and mass of other hardware, by permitting the use of compact highpressure thrust chambers, while reducing liquid tank pressures and minimizing inert gas storage. While this principle has been essential to successful launch vehicles for decades, it is virtually unknown to small systems. If pump-fed propulsion can be implemented on a $100-\mathrm{kg}$ scale, it could be useful for Mars sample return. ${ }^{1}$ Other potential applications include visiting the moons of Earth and other planets, small upper stages, and any aggressive maneuver that needs a high velocity change at a significant acceleration. If pump gas consumption can be sufficiently low, it would also be possible to enhance the net specific impulse of in-space propulsion systems. ${ }^{2}$

The subject of this paper was derived from a pump flight-tested with monopropellant hydrazine in $1994 .{ }^{3}$ Eliminating excess leakage of the high temperature drive gas was gradually accomplished over some years, by finding a way to conduct heat from soft seals into the pumped liquid. ${ }^{4}$ The latest effort, funded by NASA's Mars Technology Program, has incorporated similar cooling features into a low-mass, high-throughput design iteration.

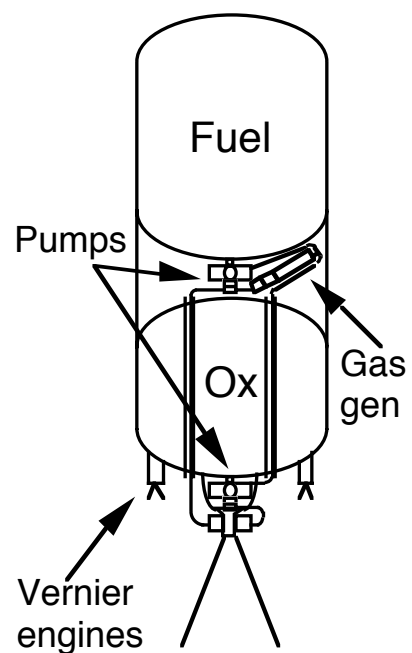

Fig. 1. Stage Concept.

\section{Pump-fed Propulsion System}

Figure 1 illustrates a lightweight stage configuration that would result from implementing launch vehicle design principles with reciprocating pumps. The walls of low-pressure tanks constitute primary vehicle structure, and there are no significant gas storage vessels. The engine operates at a much higher pressure, and is therefore more compact than a conventional satellite engine having similar thrust. Such a stage could be implemented over a range of sizes. As one example, overall length could be about 1 meter, for a total wet mass below $100 \mathrm{~kg}$. The engine, although small and lightweight, would have sufficient thrust to lift the stage and a payload against gravity. If all the parts can be sufficiently light, the stage propellant mass fraction would approach or exceed $90 \%$.

Conventional launch vehicles use pump-fed engines that include turbine-driven centrifugal pumps closely integrated with the thrust chamber. A significant difference here is that the pumps are more closely associated with the tanks. This feature suggests reserving the term "engine" to refer to only the thrust chamber, nozzle, injector, and thrust control valves, consistent with existing terminology for small engines that are pressure fed. Also consistent with this terminology choice is the notion of a pump-fed propulsion system, rather than a pump-fed engine.

\footnotetext{
* PO Box 808, Mail Stop L-413, AIAA Senior Member.
} 
A key requirement is that the pumps and their power source must have a mass significantly below the savings in tank and engine mass, relative to pressure-fed propulsion. If acceleration and $\Delta \mathrm{v}$ need to be high, an electrically powered pump, for example, would be too heavy. As on launch vehicles, the pumps must be lightweight, efficient, powerful machines, powered by reacted propellant. Figure 2 is a simplified schematic diagram of a pump-fed propulsion system, shown with space propellants. In addition to tanks, pumps, and engines, there is a gas generator which uses a small percentage of the fuel to power the pumps. In order to deliver propellant that drives itself, a pump must have a liquid discharge pressure greater than the pressure of the drive gas. A monopropellant gas generator circuit with a piston pump has been tested on various occasions with hydrazine, ${ }^{5,6}$ and separately using hydrogen peroxide. ${ }^{7}$

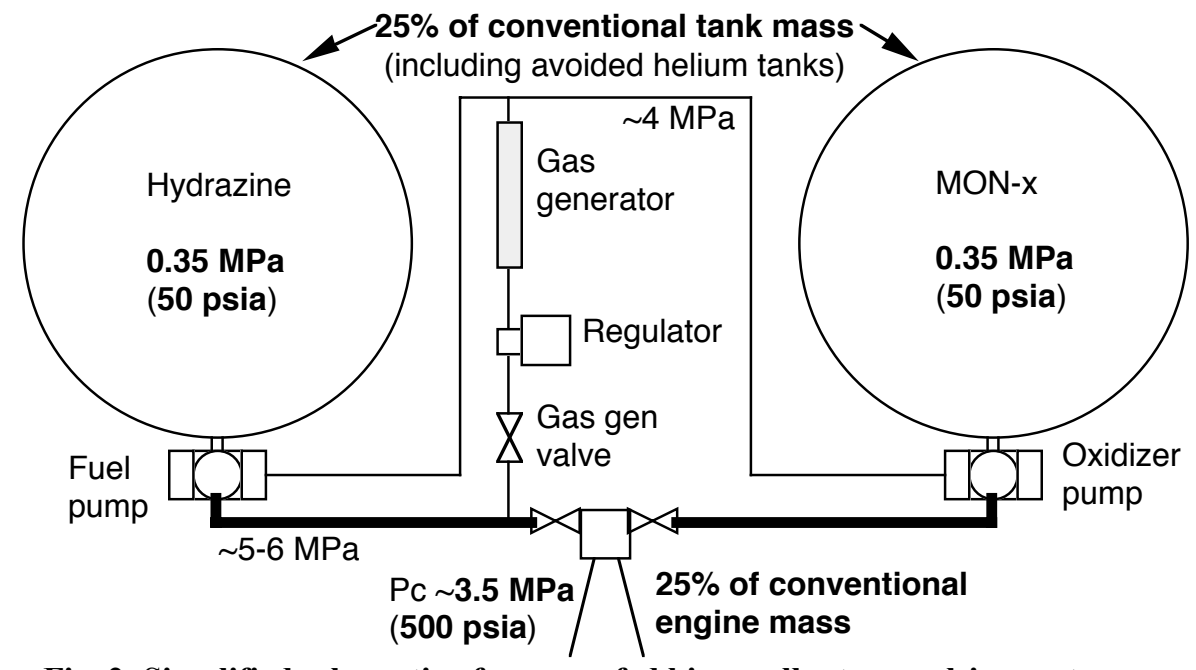

Fig. 2. Simplified schematic of a pump-fed bipropellant propulsion system.

The nature of reciprocating pumps yields a unique operational feature that is not possible with turbopumps. The pumps, and the system, can maintain full pressure without flow. The pressure regulator in series with the gas generator ensures consistent operation. One or more high-pressure engines may be connected to the pump discharge ports and operated independently, e.g. the vernier engines shown in Fig. 1.

\section{Reciprocating Pump}

Displacement type pumps are in principle very straightforward and can be made to work on a small scale more readily than turbopumps.. Gas pressure is applied almost directly to the liquid, without shaft power or rotating parts.

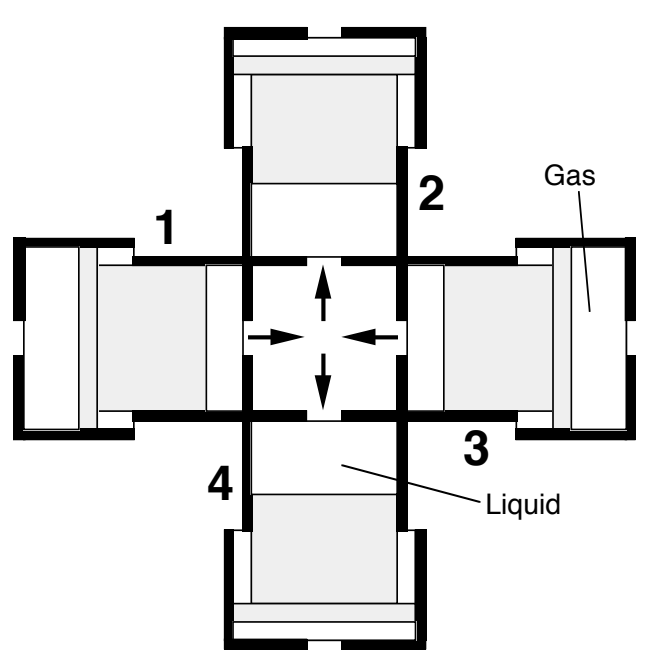

Fig. 3. Quad piston pump configuration.
Power consumption (gas flow) stops at full pressure if liquid flow is shut off (not possible with a turbine).

Figure 3 shows a cross section diagram representing a fourchamber "quad" piston pump. Liquid flows into and out of the inner cylinders through a central block, which contains 8 check valves (not shown). Gas is supplied to the outer power cylinders, controlled by intake-exhaust valves (also omitted in Fig. 3). The gas cylinders are larger in diameter than the liquid cylinders. The area ratio makes it possible for delivered propellant to power its own pump, as in Fig 2.

Arrows in Fig. 3 indicate motion. At the time shown, cylinder numbers 1 and 3 are approaching the end of a power stroke, while cylinders 2 and 4 have nearly refilled with propellant. The gas valves are controlled so that opposite pistons always move toward or away from each other in unison to cancel moving mass effects. Continuous flow is obtained by a control scheme that provides overlap of the power strokes, i.e. cylinders 2 and 4 become pressurized with gas slightly before pistons 1 and 3 reach their limit and their cylinders are vented. 
The configuration shown here has a low-pressure exhaust stroke during liquid refilling, driven only by the propellant tank pressure. For this reason, performance is best when pumps are closely connected to the tank without flow restrictions, as indicated in Fig. 1. Ideally, pump exhaust at high pressure would be injected into the main thrust chamber for a system performance advantage, but doing so would add significant complexity and mass to both the pump and the propulsion system.

Although it may be relatively straightforward to build heavy prototypes that demonstrate all the principles explained above, designing and building a high-performance reciprocating pump has not occurred rapidly. Pitfalls include excess mass, gas valve leakage, and liquid check valve leakage. High liquid throughput is critically dependent upon achieving rapid refill from a low pressure tank. Maintaining high discharge pressures at high flows requires minimizing losses in the gas intake valve and the liquid outlet check valves. A significant amount of gas might be wasted when the valves switch. Mechanical stress levels must be chosen to balance lifetime and weight requirements. Seals and valve seats can wear out or deform. Valve pieces can bend. Gas consumption must be traded against hardware thermal limits. Gas valve timing is a balancing act between poor volumetric efficiency and failing to achieve overlap for continuous flow. Liquid valves might also respond too slowly. For all these reasons, the latest results reported in this paper are thought to represent a meaningful advance. For the first time, a set of performance curves consistent with the needs of a flight propulsion system is presented.

\section{Test Hardware}

The test article has a mass of 309 grams when fully assembled as in Fig. 4. The large curved tubes are the gas distribution manifold. Two small fittings (far left) accommodate pressure and temperature instrumentation, while a gas source is connected to the $6.35 \mathrm{~mm}(0.25 \mathrm{inch})$ tube fitting below them.

One of the small $1.6 \mathrm{~mm}(.062 \mathrm{inch})$ diameter tubes

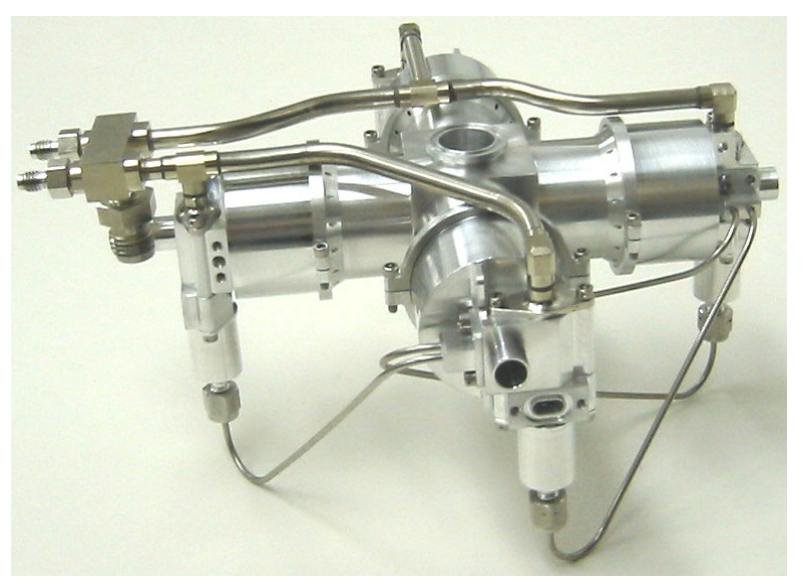

Fig. 4. Lightweight leak tight quad piston pump. transmits gas to each intake-exhaust valve actuator (Fig. 5), from an adjacent cylinder when the cylinder is pressurized, and vents the actuator when the adjacent cylinder is vented. Applied pressure pushes a valve poppet against its intake seat and opens the exhaust. The pneumatic signals are switched when a piston approaches the end of its power stroke. The small diameter seals in Fig. 6 are part of the switching valve.

The liquid inlet port is the large bore at the center of Fig. 4, and the opposite side of the block has separate outlet bores, visible in Fig. 6. One set of parts was tested to structural failure. Burst pressures exceeded $10 \mathrm{MPa}$ (1450 psi) for the power cylinders and $15 \mathrm{MPa}$ (2175 psia) for the pumping cylinders.

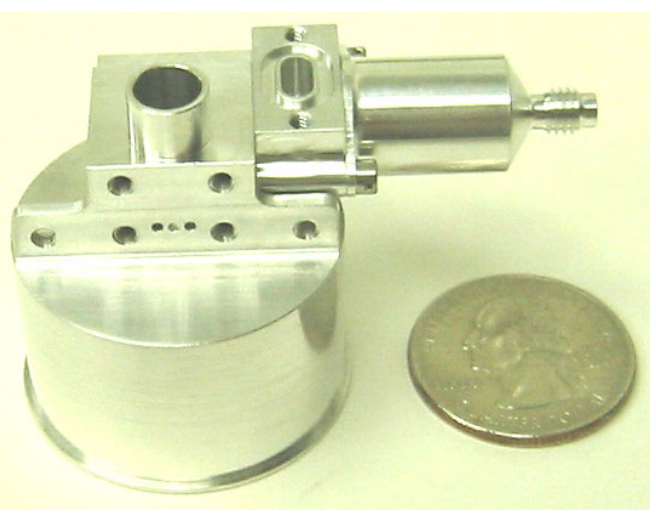

Fig. 5. Gas cylinder head has integral valve.

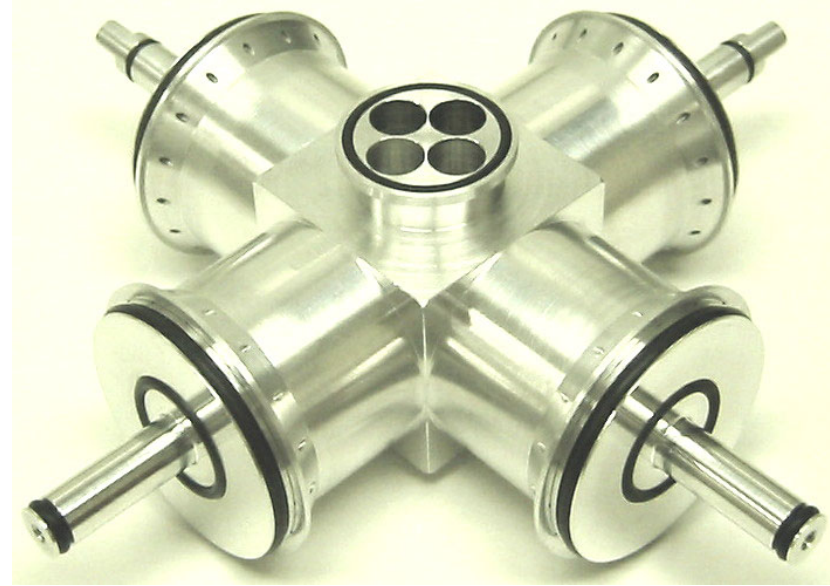

Fig. 6. Pistons in liquid cylinder block. 


\section{Test Configuration and Raw Data}

In order to permit the fastest possible refilling at a low pressure, the pump was connected close to a water source tank, partly visible at the top of Fig. 7. Discharge liquid flowed through a $6.35 \mathrm{~mm}(0.25 \mathrm{in})$ diameter tube (foreground, left). This tube led to a valve in series with an adjustable restriction, then into a collection vessel that could easily be weighed after each individual test. Helium at $4.2 \mathrm{MPa}(600 \mathrm{psig})$ was supplied to the pump through

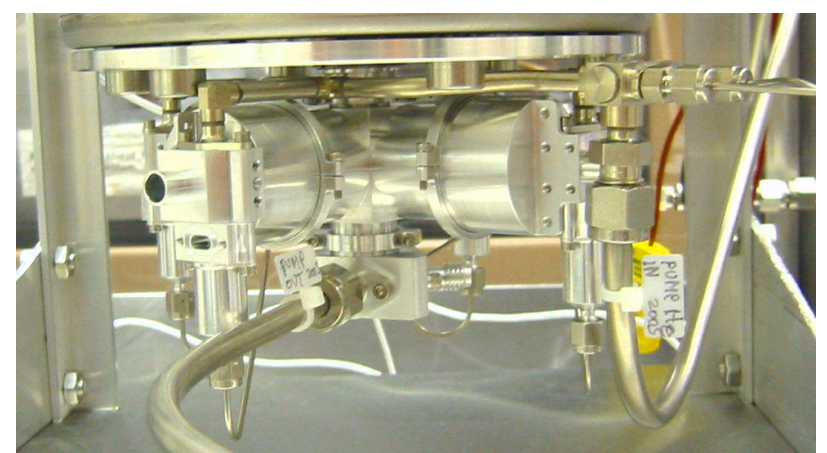

Fig. 7. Pump installed below tank, on test stand. another tube visible at the right in Fig. 7. In future tests, a source of warm gas from reacted propellant would be connected instead.

Test preparations included loading water into the 9liter tank and pressurizing it with air. A typical test run consisted of initiating digital pressure recording, opening a helium valve, then finally opening the liquid discharge valve for a period of time. Figure 8 shows one such test at 2 different time scales. One item of interest is how smooth the transition is, when adjacent pump cylinders switch. Gas demand must necessarily increase briefly, so pressure dips occur.

The raw data has liquid pressure spikes, which appear very differently from one switchover event to the next. Aliased ringing, at frequencies too high for $6 \mathrm{kHz}$ sampling to capture, is suspected. The amplitude and freqency both change dramatically depending on how the pressure transducer is connected, which suggests that the spikes are essentially an artifact. No serious attempt has yet been made to design a lightweight accumulator, but the frequency of oscillation relative to the pump frequency indicates that such an accumulator, if needed, would be very small relative to the pump displacement volume. The lower half of Figure 8 shows the same data after digital filtering. The result indicates that the actual discharge pressure interruption is on the order of $10 \%$ for $1 \mathrm{~ms}$.
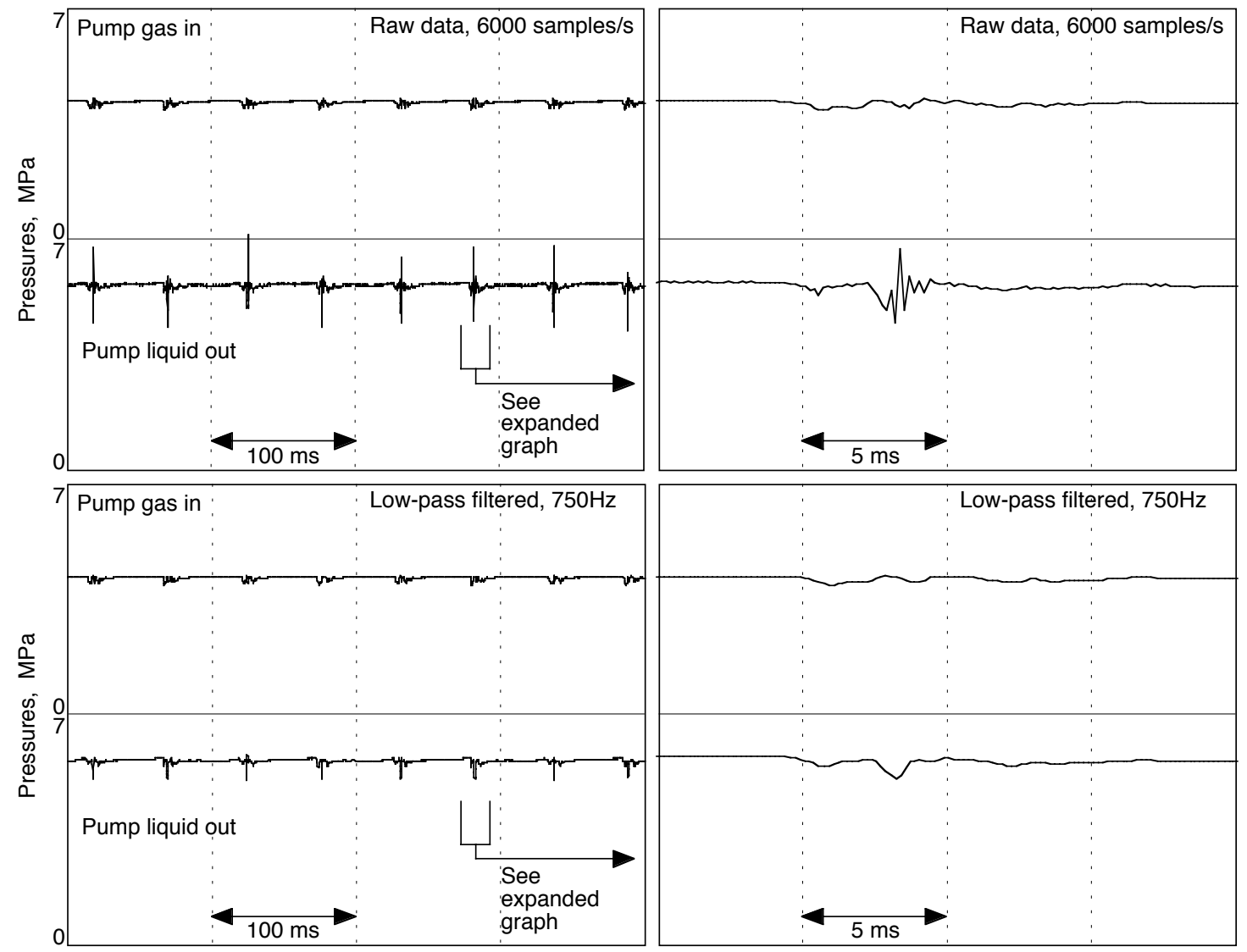

Fig. 8. Pressures recorded while pumping water with helium power. 


\section{Pressure and Flow}

Numerous test runs were performed, using different discharge restrictions in order to vary flow. One particular test series yielded the curves in Fig. 9. The pair of data points at each flow represents average pressures during several seconds of steady pump cycling. As in any fluid system, there are pressure losses that increase with flow. At

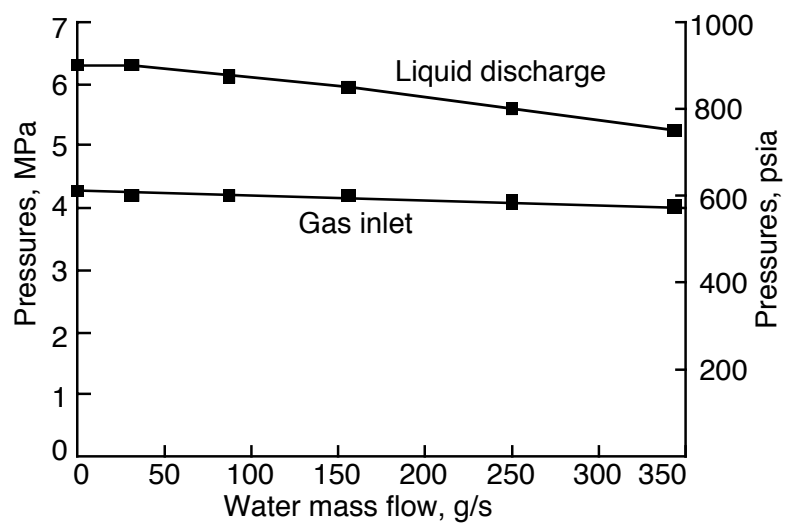

Fig. 9. Pressures fall somewhat as flow increases. zero flow, the liquid-to-gas pressure ratio is very close to the piston area ratio, 1.5. At higher flows, the outlet check valves are the primary contributor to reduced discharge pressure.

The results are very encouraging because the new lightweight pump has reached about the same flow as the 1994 hydrazine pump, almost twice the capability of the previous design for a leak-tight pump. Fluid power exceeds 1750 watts at the right edge of Fig. 9. Based only on data here, a pair of such pumps could deliver fuel and oxidizer at roughly $600 \mathrm{~g} / \mathrm{s}$, which is sufficient for $1800 \mathrm{~N}(\sim 400 \mathrm{lb})$ thrust at $\mathrm{I}_{\mathrm{SP}}=310 \mathrm{~s}$. It should be cautioned, however, that the maximum capability may be lower when decomposed hydrazine is used for power.

\section{Frequency and Displacement Efficiency}

Another performance metric is how completely the internal liquid volume of the pump chambers is used to displace liquid. Each cylinder has an ideal displacement of $8.0 \mathrm{cc}$ between piston hard stops, or $32 \mathrm{cc}$ per pump cycle. Margin is needed at both ends of the piston stroke, to ensure continuous flow, and to avoid high stresses that

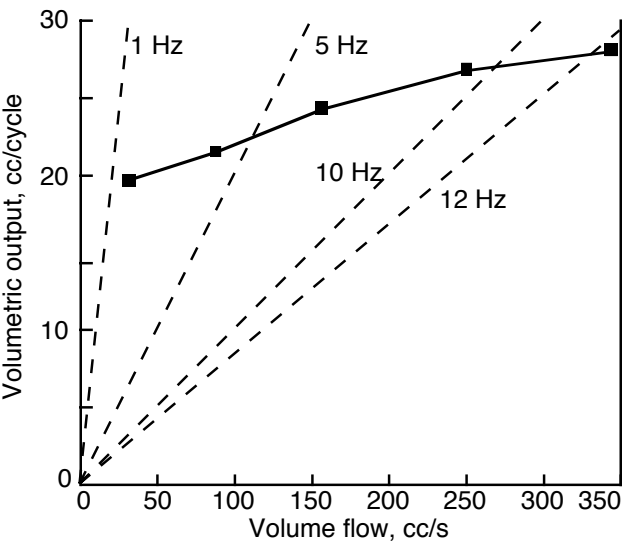

Fig. 10. Liquid displacement and frequency. would result from impact. The valve switching time is under 10 ms for helium drive, independent of piston speed. Allowing sufficient time for the valves at the highest expected piston speeds requires the piston travel to be less at low speeds. For helium, the low-speed switching point was set near $3 / 4$ of the stroke.

Figure 10 shows discharge volume per cycle, calculated from the same test series used for Fig. 9. The graph indicates that the switching point was chosen correctly, because the difference between low flow and high flow is about $1 / 4$ of the ideal displacement. At each end of the curve, about $4 \mathrm{cc}$ is unused. This includes some reverse liquid flow needed to close check valves, as well as the stroke margin to avoid the hard stops. The actual pumping displacement approaches $90 \%$ of the ideal displacement, so further improvement would yield diminishing returns.

\section{Leakages and Longevity}

In the absence of discharge flow, the pump maintains full pressure without piston motion or gas consumption. The extent to which this statement is not perfectly true is indicative of leakage. In one test, the pump was held in a no-flow state for 10 minutes. The pistons gradually moved, as liquid leaked back to the tank through the inlet check valves. The mean cycling period, $67 \mathrm{~s}$, indicates a mean liquid leakage of $0.3 \mathrm{~g} / \mathrm{s}$ above $6 \mathrm{MPa}$, or $0.15 \mathrm{~g} / \mathrm{s}$ through an average individual inlet check valve. The maximum rate, during the shortest half-cycle, was within twice that.

Gas leakage past the piston seals and exhaust valve seats was measured by pressurizing all four power cylinders simultaneously with the pump dry. The helium loss was approximately 1 standard cc per minute at $4.2 \mathrm{MPa}$, about one millionth of the gas consumption rate at full pump flow. In an actual propulsion system, the gas source would be turned off during long quiescent periods, so further improvement is not likely to be necessary.

More than $18 \mathrm{~kg}$ of water had been pumped by the first test article as this paper was being finalized. No maintenance or repairs were needed, and there was no obvious indication of increasing leakage. 


\section{Tank Pressure Thresholds}

Continuous operation of the pump requires a given cylinder to refill completely from the low pressure tank before it is called upon for another power stroke. Fundamentally, this sets a maximum flow limit depending on tank pressure, only weakly dependent on discharge pressure. At the limit, successive pump cycles become shorter as frequency rises and the extent of refilling is reduced further for each subsequent cycle. Finally, none of the cylinders can deliver liquid when they are all empty. This stall effect is beneficial in that it prevents excessive speeds that

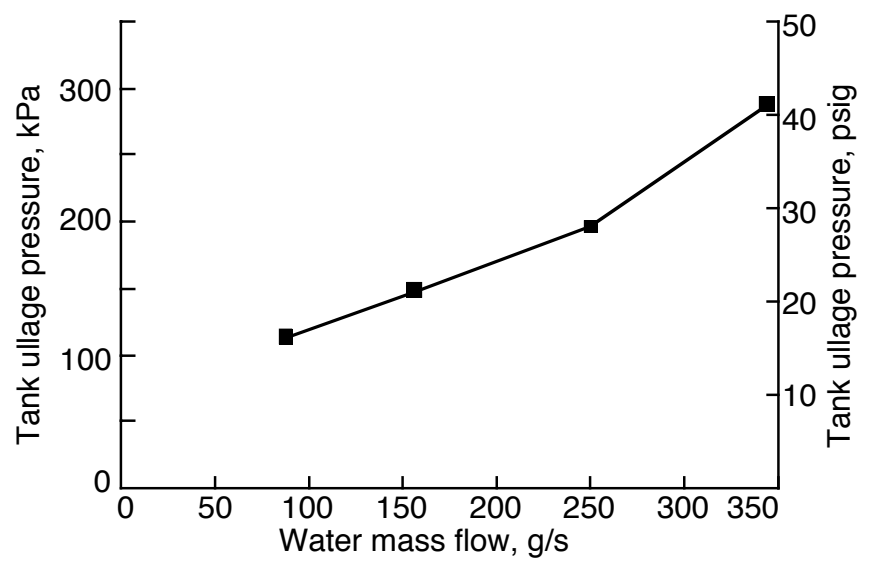

Fig. 11. Minimum required tank pressure above ambient. would result in piston impact. Of course stalling is detrimental during a propulsive maneuver, even though it is benign for the hardware and the system can be restarted. Sufficient margin avoids stalling, e.g. the pump should be run at up to only $80 \%$ of the maximum possible flow.

In Fig. 11, the curve does not go to the origin, because there is a friction limit, i.e. the slowest consistent refill requires a minimum tank pressure in the neighborhood of 1 atmosphere above the local ambient.

As noted earlier, properties of the drive gas affect performance. In particular, time is needed for exhaust venting before refilling can begin. Decomposed hydrazine, for example, will require a longer exhaust time than helium.

\section{Gas Consumption}

Delta mass measurements of a helium source vessel were made to determine the quantity that flowed while powering the pump. Two identical tests were done at $250 \mathrm{~g} / \mathrm{s}$ water flow for $10 \mathrm{~s}$ duration each. One test consumed $27 \mathrm{~g}$ of $\mathrm{He}$, and the other used $29 \mathrm{~g}$. The difference roughly equals the measurement uncertainty, determined while

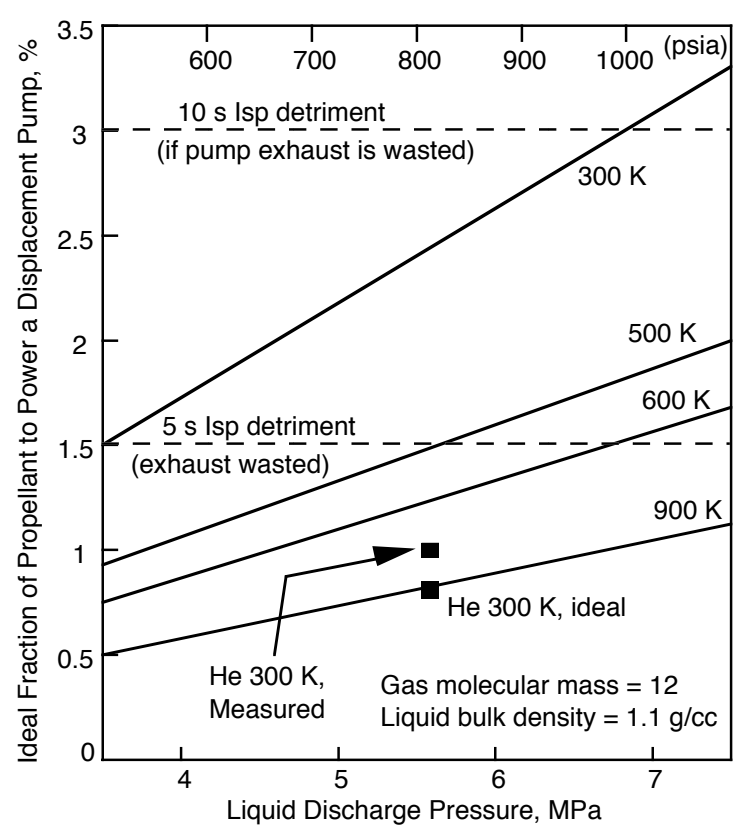

Fig. 12. Gas requirements for pump drive. practicing the weighing technique. To within about 10 percent accuracy, the helium mass was 1.1 percent that of the water pumped, at $5.58 \mathrm{MPa}(809 \mathrm{psia})$ average discharge pressure. Accuracy depends on the duration of pump operation, and confidence depends on measurement repeatability, so it is expected that this result will be refined and verified as more lifetime is accumulated on the pump. A thermocouple at the pump gas inlet indicated $295 \mathrm{~K}(73 \mathrm{~F})$ for both runs.

Figure 12, after Ref. (2), offers a convenient way to put the measurement in perspective. The curves are based on the assumption that decomposed hydrazine, as an ideal gas, displaces fuel and oxidizer having a bulk density of $1.1 \mathrm{~g} / \mathrm{cc}$. Given equal ratios for temperatures and molecular weights, the lower curve for $900 \mathrm{~K}$ decomposed hydrazine also represents the ideal situation for helium power at $300 \mathrm{~K}$.

The lower labeled point in Fig. 12 indicates the ideal quantity of helium required to displace liquid at the tested pump discharge pressure. The nearby upper point is the test result. Most of the difference is not wasted gas per se, but rather is attributable to the pressure drop through the pump outlet check valves. The result is very encouraging. Efficient usage of pump drive gas is not only good for system $\mathrm{I}_{\mathrm{SP}}$, but it also reduces the size and mass of the gas generator and a heat exchanger that may be needed to cool the decomposed hydrazine. If the working temperature of the latter is above $600 \mathrm{~K}$, extrapolating the helium test result would predict a mere 5-s I $\mathrm{ISP}_{\mathrm{SP}}$ detriment to a pump-fed propulsion system, relative to the engine alone. There would be a net benefit because a high chamber pressure, made possible by pumps, offers 10-15 s more than conventional space engines. 


\section{Conclusion}

A four-chamber reciprocating piston pump design has been refined, and an initial round of testing with cold inert fluids has been completed. The new hardware is essentially flight weight and leak tight. Throughput of a pair of such pumps would be sufficient for thrust at least as high as $1000 \mathrm{~N}(225 \mathrm{lb})$. Remaining work includes testing with drive gas from reacted propellant, and pumping liquid propellants. Mission duration testing, as well as extended life testing, are also of interest. Continued success would be followed by subsystem testing, and finally complete system testing of a small-scale pump-fed propulsion system. The latter would need a new lightweight, compact, highpressure bipropellant engine. Such a propulsion system has various potential applications, one of which is Mars-toEarth transportation for geology samples on a smaller scale than conventional technology permits.

\section{Acknowledgment}

Progress described here was funded and guided by NASA's Mars Technology Program. The author wishes to thank Ron Reeve and others at the Jet Propulsion Laboratory. Appreciation is due to Dean Urone of LLNL for design contributions and for preparing high quality fabrication drawings.

This work was performed under the auspices of the U.S. Department of Energy, by the University of California, Lawrence Livermore National Laboratory under Contract W-7405-Eng-48.

\section{References}

${ }^{1}$ Whitehead, J.C., “Trajectory Analysis and Staging Trades for Smaller Mars Ascent Vehicles," J. Spacecraft, Accepted for publication, 2005. Revised from "Mars Ascent Propulsion Trades with Trajectory Analysis," AIAA Paper 2004-4069, July 2004.

${ }^{2}$ Whitehead, J.C., "Reciprocating Pump Systems for Space Propulsion,” AIAA Paper 2004-3836, July 2004.

${ }^{3}$ Whitehead, J.C., Colella, N.J., and Pittenger, L.C., "Design and Flight Testing of a Reciprocating Pump Fed Rocket," AIAA Paper 94-3031, June 1994.

${ }^{4}$ Whitehead, J.C., "Test Results for a Reciprocating Pump Powered by Decomposed Hydrogen Peroxide," AIAA Paper 20013839, July 2001.

${ }^{5}$ Maybee, J.C., Swink, D.G., and Whitehead, J.C., "Updated Test Results of a Pumped Monopropellant Propulsion System," JANNAF Propulsion Meeting Proceedings, CPIA Pub. 602 Vol. 1, p.131, November 1993.

${ }^{6}$ Frei, T.E., Maybee, J.C, and Whitehead, J.C., "Recent Test Results of a Warm Gas Pumped Monopropellant Propulsion System," AIAA Paper 94-3393, June 1994. 2002.

${ }^{7}$ Whitehead, J.C., "Hydrogen Peroxide Gas Generator Cycle with a Reciprocating Pump," AIAA Paper 2002-3702, July 